\title{
Dietary patterns of adolescents in Germany - Associations with nutrient intake and other health related lifestyle characteristics
}

\author{
Almut Richter ${ }^{1,2^{*}}$, Christin Heidemann², Matthias B Schulze ${ }^{3}$, Jutta Roosen ${ }^{1}$, Silke Thiele ${ }^{4}$ and Gert BM Mensink ${ }^{2}$
}

\begin{abstract}
Background: The aim of this study was to identify dietary patterns among a representative sample of German adolescents and their associations with energy and nutrient intake, socioeconomic and lifestyle characteristics, and overweight status.

Methods: In the analysis, data from the German Health Interview and Examination Survey for Children and Adolescents were used. The survey included a comprehensive dietary history interview conducted among 1272 adolescents aged 12 to 17 years. Dietary patterns were determined with principal component analysis (PCA) based on 48 food groups, for boys and girls separately.

Results: Three dietary patterns among boys and two among girls were identified. Among boys, high adherence to the 'western' pattern was associated with higher age, lower socioeconomic status (SES), and lower physical activity level (PA). High adherence to the 'healthy' pattern among boys, but not among girls, was associated with higher SES, and higher PA. Among boys, high adherence to the 'traditional' pattern was associated with higher age. Among girls, high adherence to the 'traditional and western' pattern was associated with lower age, lower SES and more hours watching TV per day. The nutrient density of several vitamins and minerals, particularly of B-vitamins and calcium, increased with increasing scores of the 'healthy' pattern among both sexes. Conversely, with increasing scores of the 'western' pattern among boys, most nutrient densities decreased, particularly of fibre, beta-carotene, vitamin $D$, biotin and calcium. Among girls with higher scores of the 'traditional and western' pattern, nutrient densities of vitamin $A, C, E, K$ and folate decreased. Among boys, high adherence to the 'traditional' pattern was correlated with higher densities of vitamin $B_{12}$ and vitamin $D$ and lower densities of fibre, magnesium and iron. No significant associations between dietary patterns and overweight were found.

Conclusions: Higher scores for dietary patterns characterized by higher consumption of take away food, meat, confectionary and soft drinks ('western' and 'traditional and western') were found particularly among 16- to 17years old boys and among adolescents with lower SES. These patterns were also associated with higher energy density, higher percent of energy from unsaturated fatty acids and lower percent of energy from carbohydrates as well as lower nutrient densities of several vitamins and minerals. Therefore, nutritional interventions should try to focus more on adolescents with lower SES and boys in general.
\end{abstract}

Keywords: Dietary patterns, Adolescents, Nutrition epidemiology, Principal component analysis

\footnotetext{
* Correspondence: richtera@rki.de

${ }^{1}$ Marketing and Consumer Research, Technische Universität München, Alte

Akademie 16, 85354 Freising, Germany

Full list of author information is available at the end of the article
} 


\section{Background}

The life stage of childhood and adolescence is important for the establishment of eating behaviours [1-3], which are often carried into adulthood [4-7]. Therefore, diet in the early stage of life influences health not only during the physical development, but also later in life [8-10]. The high prevalence of obesity and nutrition related diseases highlights the need to focus on nutritional interventions early in life [11]. Accordingly, knowledge about actual nutritional intake and diet behaviour among children and adolescents is essential.

Information on dietary patterns reflect the overall nutritional behaviour better than information on single foods or nutrients [12]. Therefore, the analysis of dietary patterns gives a more comprehensive impression of the food consumption habits within a population. Dietary guidelines based on preferred dietary patterns may be easier to understand and transported to the public than nutrient intake recommendations, because people are aware of their food consumption but not their nutrient intake.

Adolescence is a special stage of life often full of personal changes. Thus, adolescents could benefit from recommendations which are close to the existing food habits of their age group.

Associations between nutrition and health are complex and often influenced by many factors. Often there is a high correlation between nutrients and between foods which may complicate the interpretation of all relevant intake variables within multiple regression analysis. The application of statistical techniques to reduce the complexity of diet to a smaller number of dimensions, such as principal component analysis, can be useful in such cases. Resulting dietary patterns can than be used to evaluate associations between nutrition and health related measures (e. g. anthropometric measures) and diseases.

Most of the previous studies on dietary patterns of adolescents are based on relatively small or non-representative samples, e. g. school classes [4,13-21]. Until now, there have been only a few European studies on population based samples, including studies from North Ireland among persons older than 16 years [22] and studies of children and adolescents from Spain [23], the Balearic Islands [24] and Scotland [25]. Outside Europe, dietary patterns in representative samples of adolescents were analysed in Mexico [26], Australia [27] and Korea [28,29].

Therefore, the aim of this study was to identify dietary patterns among a representative sample of German adolescents and their associations with energy and nutrient intake, socioeconomic and lifestyle characteristics, and overweight status.

\section{Methods}

\section{Study population}

The German Health Interview and Examination Survey for Children and Adolescents (KiGGS) is a populationbased, nationally representative, cross-sectional study [30]. The sample was drawn with a two-stage clustered and stratified sampling procedure. In the first stage, 167 sample points (initially 150 and later 17 additional points) representative for German communities were selected and stratified by federal state and community size. In the second stage, for every age, almost the same number of participants was randomly selected from the population registries. From May 2003 to May 2006, a total of 17,641 children and adolescents aged 0 to 17 years, participated in KiGGS. The overall response rate was $66.6 \%$. The survey was approved by the Federal Office for Data Protection and by the ethics committee of Charitè University Medicine. Each parent and participant gave informed written consent before enrolment into the survey. Design, methods and response analyses are described in detail elsewhere [31].

For the present analysis, we included a subsample of the KiGGS participants (Eating Study as KiGGS Module, EsKiMo). The participants of EsKiMo were randomly selected from the KiGGS participants in the original 150 sample points, stratified by age and sample point. A net sample size of 100 participants per age and sex was intended. In total, information of 1234 children aged 6 to 11 years and 1272 adolescents aged 12 to 17 years was obtained. EsKiMo was conducted from January to December 2006 by the Robert Koch Institute and the University of Paderborn [32]. As children and adolescents differ in their ability and willingness to cooperate and in their personal circumstances (e. g. frequency of meals outside home), two different tools for data collection were used. Parents of participants younger than 12 years were asked to complete dietary records on three given consecutive days. Participants 12 years of age and older took part in a comprehensive dietary assessment. The present analyses are based on the 622 boys and 650 girls aged $\geq 12$ to $<18$ years who took part in EsKiMo. The participation rate of EsKiMo for this age group was $64.7 \%$

\section{Data collection}

KiGGS includes a range of physical examinations and tests as well as questionnaires filled out by parents and children aged 11 years and older. Parents were asked about their educational and occupational status and available household family income. Socioeconomic indicators were computed from each of these three components ranging from 1 to 7 . A summary family socioeconomic status (SES) index was calculated for 
every participant ranging from a minimum of 3 to a maximum of 21. A higher SES index corresponds to a higher status [33]. City size was assessed and grouped into small (under 5,000 inhabitants), small and middlesized (5,000 to 99,999 inhabitants) and big cities (100,000 inhabitants or more).

Participants of EsKiMo 12 years of age and older, were interviewed by trained nutritionists using the Dietary Interview Software for Health Examination Studies (DISHES), a computerised face-to-face modified dietary history instrument designed to assess usual dietary intake within a reference period of the last four weeks. DISHES was developed at the Robert Koch Institute and was used in several nutrition surveys [34,35]. The relative validity of DISHES for adults was assessed in comparison with 3-d weighted dietary records and a 24-h dietary recall and revealed correlations for nutrient intakes in a reasonable range $(0.34$ to 0.69 for $3-\mathrm{d}$ weighted dietary records, 0.27 to 0.65 for $24-\mathrm{h}$ recall) [34]. In the DISHES-interviews, firstly, the usual meal patterns of the participant were assessed. Secondly, food groups consumed during each meal were obtained by a check list. Lastly, following the meal structure of the day, the frequencies and amounts of all specific foods and drinks consumed during each meal were assessed. Estimations of portion sizes are facilitated through use of standardized tableware models and a picture book with different reference portion sizes. In DISHES, all food items are coded automatically with the German Food Code and Nutrient Database (BLS II.3) [36]. DISHES was updated and adapted for this study and the target group of adolescents. For instance, additionally foods, not included in the BLS but consumed by adolescents, were incorporated. The nutrition interviews were conducted primarily at the adolescent's home or in cases when this was not possible, in a survey van. For this, every sample point was visited by one of the interviewers. The interviews were equally distributed over the year, thus, the issue of seasonality was accounted for on the group level. The average duration of the interview was 49 minutes. Participants received $10 €$ as an incentive along with a personal evaluation of their interview (e. g. nutrient intakes in comparison to reference values). To improve data quality, voice recorders were used to check participant answers if questionable data were detected.

In addition to the DISHES interview, EsKiMo included questions about specific nutritional, lifestyle and behavioural aspects. These questions referred to dietary supplement use ('Do you use dietary supplements (vitamins, minerals) e. g. pills, drops? Which products? How often did you take these products during the last four weeks?'), frequency of family meals ('Do you have joined meals at home? Which meals: breakfast, lunch, dinner?
How often? Every day, three to five times a week, one to two times a week, less, never'), frequency of eating a warm lunch at school ('Do you have the possibility to eat a warm lunch at school? If yes: How often do you eat a warm lunch at school? Daily, tree to four times a week, one to two times a week or more seldom') and self-reported cooking skills ('How good are your cooking skills? Very good, good, ordinary, not good, bad, I don't cook'). Questions about leisure time activities referred to frequency of physical activity and time spent watching television per day ('In your leisure time, how often are you physically active in such a way that you start to sweat or become slightly out of breath? Never, almost every day, about three to five times a week, about one to two times a week, about one to two times a month' and 'How long do you usually watch TV per day? Never, 30 minutes, one to two hours, three to four hours, more'). Body mass index (BMI) was calculated from self-reported body height and weight. Participants with a BMI above the $90^{\text {th }}$ percentile of the age and gender specific reference values [37] were categorised as overweight.

\section{Statistical analyses}

In the DISHES interviews, 2280 different foods and beverages were reported. These foods were combined into 48 food groups (Table 1). Therefore, commonly used food groups were differentiated according to similarities in nutrient profiles. For every food group, the mean amount consumed daily in grams was calculated for each individual and standardized to a mean of 0 and standard derivation of 1 .

From previous analyses it was known that food consumption was different between sexes in this age group [38]. Therefore, the analyses were separately conducted for boys and girls. Dietary patterns were identified using principal component analysis (PROC FACTOR method = prin) on the 48 food groups. The resulting components were linear combinations of the included variables and explained as much of the variation in the original variables as possible. The components were rotated by an orthogonal transformation (resulting in uncorrelated components) to achieve a simpler structure with greater interpretability. To identify the number of principal components to be retained, the following criteria were used: the criterion of eigenvalues exceeding 1 (the interpretation of this criterion being that each component should explain a larger amount of variance than a single standardized variable in order to be retained), the scree plot (which is a graphical presentation of eigenvalues) and the interpretability of each component [39]. For good interpretability of each component, an adequate number of food groups with high loadings within a component are necessary. According to Hatcher 2007 
Table 1 Factor loadings* of the food groups in the dietary patterns (principal components) identified among German adolescents

\begin{tabular}{|c|c|c|c|c|c|}
\hline \multirow[b]{3}{*}{ Food groups } & \multicolumn{5}{|c|}{ Dietary patterns } \\
\hline & \multicolumn{2}{|l|}{ Boys $(n=622)$} & \multicolumn{2}{|c|}{ Girls $(n=650)$} & \multirow[b]{2}{*}{ Traditional and western } \\
\hline & western & healthy & traditional & healthy & \\
\hline$\overline{\text { Pizza }^{\dagger}}$ & 0.66 & & & & 0.32 \\
\hline Doner kebab & $\underline{0.59}$ & & & & 0.26 \\
\hline Burger & $\underline{0.57}$ & & & & 0.29 \\
\hline Soft drinks & 0.55 & -0.24 & 0.29 & & 0.46 \\
\hline French fries & $\underline{0.53}$ & & & & 0.32 \\
\hline Alcoholic drinks & $\underline{0.42}$ & & 0.25 & & \\
\hline Chicken & $\underline{0.41}$ & 0.32 & & $\underline{0.51}$ & \\
\hline Ketchup ${ }^{\ddagger}$ & $\underline{0.40}$ & & & & 0.26 \\
\hline Salty snacks & 0.37 & & & & \\
\hline Meat (except chicken) & 0.33 & 0.28 & 0.37 & 0.21 & 0.46 \\
\hline Pasta & 0.33 & & & 0.26 & $\underline{0.45}$ \\
\hline Confectionary & 0.33 & & & & 0.46 \\
\hline Sausages $^{\S}$ & 0.27 & & & & 0.46 \\
\hline Legumes & 0.25 & $\underline{0.41}$ & & 0.47 & 0.23 \\
\hline Warm sauces & 0.25 & & 0.21 & 0.31 & 0.37 \\
\hline Rice & 0.23 & $\underline{0.59}$ & & $\underline{0.65}$ & \\
\hline Wholemeal bread & -0.29 & & & & -0.21 \\
\hline Salad vegetables & & $\underline{0.59}$ & & $\underline{0.44}$ & \\
\hline Fruits & & $\underline{0.57}$ & & 0.35 & \\
\hline Other vegetables" & & $\overline{0.53}$ & 0.27 & 0.43 & \\
\hline Vegetable oil & & $\underline{0.52}$ & & $\underline{0.61}$ & \\
\hline Mushrooms & & 0.37 & & 0.35 & \\
\hline Soup & & 0.35 & & 0.59 & 0.28 \\
\hline Grain products" & & 0.35 & & & \\
\hline Fish & & 0.28 & 0.31 & 0.38 & \\
\hline Cake/cookies & & 0.25 & 0.23 & & 0.35 \\
\hline Eggs & & 0.25 & 0.35 & 0.33 & 0.21 \\
\hline Potatoes & & 0.25 & $\underline{0.56}$ & 0.29 & 0.42 \\
\hline Nuts & & 0.25 & & & \\
\hline Falafel**$^{* *}$ & & 0.24 & & 0.24 & \\
\hline Water & & 0.23 & & 0.31 & -0.36 \\
\hline Processed meat & & & 0.69 & & 0.47 \\
\hline 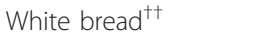 & & & $\underline{0.51}$ & & 0.38 \\
\hline Margarine & & & 0.38 & & \\
\hline Cheese & & & 0.33 & & \\
\hline Butter & & & 0.28 & & \\
\hline Meat salad ${ }^{\ddagger \neq}$ & & & 0.27 & & \\
\hline Dessert, Ice-Cream & & & 0.25 & & 0.25 \\
\hline Yoghurt & & & 0.25 & & \\
\hline Coffee & & & 0.22 & & \\
\hline \multicolumn{6}{|l|}{ Breakfast cereals } \\
\hline Jam & & & & & 0.24 \\
\hline \multicolumn{6}{|l|}{ Juices } \\
\hline \multicolumn{6}{|l|}{ Milk } \\
\hline Other milk products ${ }^{\S \S}$ & & & & & 0.20 \\
\hline
\end{tabular}


Table 1 Factor loadings* of the food groups in the dietary patterns (principal components) identified among German adolescents (Continued)

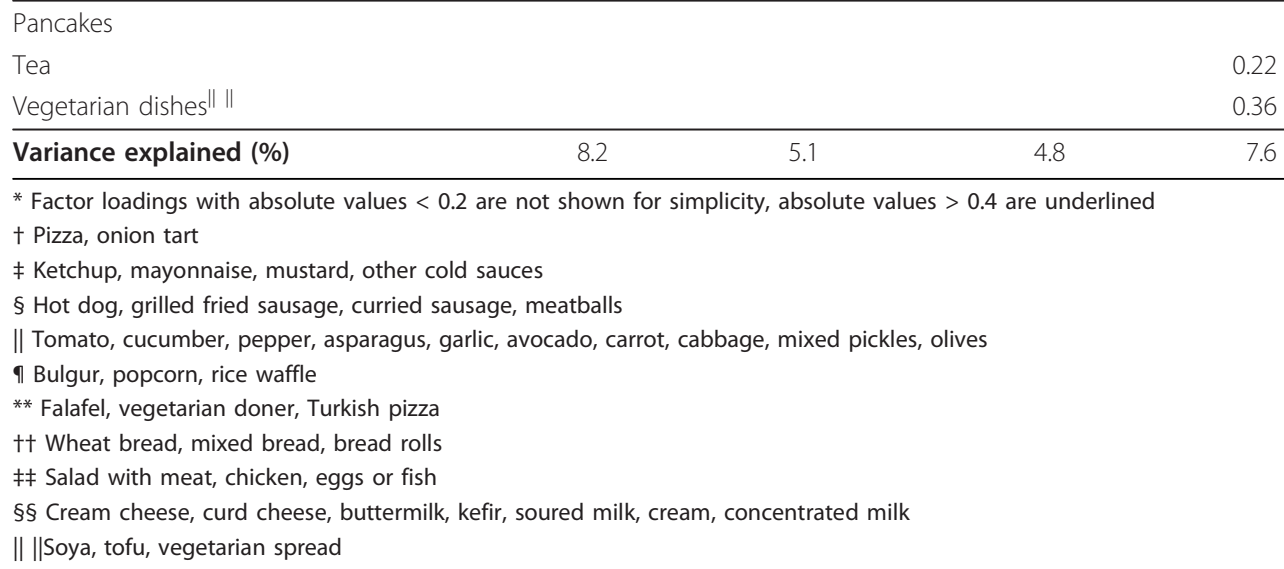

* Factor loadings with absolute values $<0.2$ are not shown for simplicity, absolute values $>0.4$ are underlined

† Pizza, onion tart

\# Ketchup, mayonnaise, mustard, other cold sauces

$\S$ Hot dog, grilled fried sausage, curried sausage, meatballs

|| Tomato, cucumber, pepper, asparagus, garlic, avocado, carrot, cabbage, mixed pickles, olives

I Bulgur, popcorn, rice waffle

** Falafel, vegetarian doner, Turkish pizza

t† Wheat bread, mixed bread, bread rolls

\#キ Salad with meat, chicken, eggs or fish

$\S \S$ Cream cheese, curd cheese, buttermilk, kefir, soured milk, cream, concentrated milk

|| ||Soya, tofu, vegetarian spread

\begin{tabular}{llllll}
\hline Variance explained (\%) & 8.2 & 5.1 & 4.8 & 7.6
\end{tabular}

[39], components with at least 3 relevant loadings, which are loadings greater than or equal to $|0.4|$, were selected. The dietary pattern score is based on the sum of the individual, standardized intake of each food group weighted by the loading of the food group. The scores rank individuals according to the degree to which they conformed to each dietary pattern. The scores were categorized into quartiles and labelled according to the food groups with high loadings. Each participant had a score for all identified dietary patterns.

To estimate nutrient and energy intake by quartiles of dietary patterns, parameters were calculated using data from the German Food Code and Nutrient Data Base (BLS II.3) [36]. To determine the nutrient content of foods eaten by the study participants which were not incorporated in the BLS, an additionally database was developed using different sources e. g. product information of the food producer.

Dietary patterns were derived without considering dietary supplements as a food group. Therefore, the analyses on nutrient intakes were also performed without taking the contribution of supplements into account.

The internal validity of the pattern structure was tested by calculating Cronbach's coefficient alpha [39].

To correct for non-response and disproportionate sample drawing, a specific weighting factor was used for all analyses [31]. Since the sample was based on a clustered and stratified design, all analyses were performed with complex survey procedures in order to take the sampling design into account.

$P$ values for trend across quartiles of dietary pattern scores were calculated in linear regression models using the survey procedure (PROC SURVEYREG). Associations between categorical variables were tested by calculation of the $\mathrm{X}^{2}$ test. $\mathrm{P}$ values $<0.05$ were considered statistically significant. For all statistical analyses the
SAS System for Windows 9.2 (SAS Institute, Cary, NC, USA) was used.

\section{Results}

\section{Dietary patterns}

We identified three major components (patterns) for boys and two for girls. These components accounted for $18.1 \%$ of the variance in food group intake in boys and $13.2 \%$ in girls. The food group loadings for each component are presented in Table 1.

Among boys, the first component was positively correlated with the intake of take away foods (pizza, doner kebab, burgers, French fries), ketchup, chicken, and other meat, pasta, alcoholic and soft drinks, salty snacks and confectionery items. This pattern was labelled 'western'. The second component was named 'healthy' as relatively high positive loadings were observed for intakes of fruits, vegetables, legumes, mushrooms, chicken, rice, vegetable oil, soup, and grain products. The third component in boys could be described as a traditional German diet, reflecting a pattern of eating traditional warm dishes and sandwiches. For this 'traditional' pattern, we obtained relatively high positive loadings for processed meat, potatoes, white bread, margarine, meat (except chicken), eggs, cheese, and fish.

Among girls, the first component was positively correlated with the intake of rice, vegetable oil, soup, chicken, legumes, vegetables, fruits, and mushrooms similar to the 'healthy' pattern of boys. Among girls, this 'healthy' pattern was also positively correlated with vegetarian dishes, eggs, fish, water and warm sauces. The second component among girls, called ,traditional and western' pattern, was positively correlated with potatoes, warm sauces, meat (except chicken), white bread, processed meat, as well as pizza, French fries, sausages, soft drinks, confectionary, cake/cookies and negatively correlated with water. 
Cronbach's alpha indicated that there was moderate inter-item reliability (among boys: 0.71 for the 'western' pattern, 0.62 for the 'healthy' pattern, 0.61 for the 'traditional' pattern; among girls: 0.67 for the 'healthy' pattern, 0.61 for the 'traditional and western' pattern).

\section{Characteristics}

Sample characteristics of the adolescents according to quartiles of each dietary pattern score are presented in Table 2 for boys and Table 3 for girls.

Boys in the higher quartiles of the 'western' pattern score were older and attended grammar school less often than those in the lower quartiles. The families of these boys had a lower SES compared to boys in the lower quartiles of this pattern. With increasing scores of the 'western' pattern, boys were less physically active and had family breakfast less often three to five times a week (Table 2).

Boys in the higher quartiles of the 'healthy' pattern more often resided in communities with more than 100,000 inhabitants, more often attended grammar school and more often live in families with a higher SES than boys in the lower quartiles of this pattern score. Additionally, these boys were more physically active, took more often dietary supplements and more often had family dinners three to five times a week than boys in the lower quartiles of this pattern.

Boys in the higher quartiles of the 'traditional' pattern were older, more often resided in communities with less than 5,000 inhabitants and less often had family dinners three to five times a week than boys in the lower quartiles of this pattern score.

Among girls, no significant differences between those with lower and higher dietary pattern scores of the healthy pattern were found (Table 3).

With higher scores of the 'traditional and western' pattern, girls were younger, had a lower SES and less often attended grammar school. In addition, girls in the higher quartiles of the 'traditional and western' pattern more often watched three to four or more hours television per day than those in the lower quartiles of this pattern.

No associations between dietary pattern scores and frequency of lunch at school, cooking skills, overweight prevalence, or the season of the nutrition interview (data not shown) were observed.

\section{Energy and nutrient intake}

Mean daily energy and nutrient intakes according to quartiles of dietary pattern scores are presented in Table 4 for boys and Table 5 for girls. Fat, protein, carbohydrates and their subgroups are presented as percentages of energy intake whereas energy, fibre, vitamins and minerals are given as nutrient densities.
With increasing scores of the 'western' pattern among boys intake of carbohydrates and polysaccharides decreased, whereas energy density, unsaturated fatty acids and alcohol increased. For this pattern, the micronutrient densities decreased from the lowest to the highest quartile, particularly of fibre, beta-carotene, vitamin $\mathrm{D}$, biotin and calcium.

With increasing scores of the 'healthy' pattern among boys, energy density and intake of alcohol decreased and intake of polyunsaturated fatty acids (PUFAs), intake of proteins and nutrient density (except for vitamin $B_{2}$, vitamin $B_{12}$ and calcium) increased.

Among boys, increasing scores of the 'traditional' pattern were associated with a higher energy density. Intake of total fat, saturated and unsaturated fatty acid, alcohol as well as vitamin $B_{12}$ and vitamin $D$ increased with increasing scores, whereas intake of total carbohydrates, intake of monosaccharides, polysaccharides, fibre, magnesium and iron decreased with increasing scores.

As for the 'healthy' pattern among boys, energy density decreased and protein density increased with increasing scores of the 'healthy' pattern among girls. In addition, increasing scores of the 'healthy' pattern among girls were associated with a lower intake of saturated and unsaturated fatty acids and a higher intake of PUFAs. Micronutrient densities increased from the lowest to the highest quartile of the 'healthy' pattern except for vitamin $\mathrm{E}$ and most of the B-vitamins. The nutrient density of vitamin $B_{12}$ was significant lower with increasing patterns scores.

With increasing scores of the 'traditional and western' pattern among girls, energy density and intake of total fat, saturated and unsaturated fatty acids increased, whereas intake of vitamin A, C, E, K and folate as well as intake of alcohol and intake of total carbohydrates, monosaccharides and polysaccharides decreased.

\section{Discussion}

With principal component analyses, we identified three dietary patterns among boys and two among girls in a population-based sample of German adolescents. Dietary patterns showed significant associations with nutrient intake. Because of the higher densities of vitamins, minerals and fibre, the 'healthy' patterns are more favourable compared to the 'western' and 'traditional and western' patterns which were associated with higher energy density, higher percent of energy from unsaturated fatty acids, lower percent of energy from carbohydrates and lower nutrient densities of several vitamins and minerals. The 'traditional' pattern was characterised by favourable as well as less favourable aspects.

Most of the dietary patterns were associated with health related lifestyle characteristics e. g. physical activity and frequency of family meals. Furthermore, the 
Table 2 Socio-demographic and behavioural sample characteristics of German boys according to quartiles of dietary pattern scores

\begin{tabular}{|c|c|c|c|c|c|c|c|c|c|c|c|c|c|c|c|c|}
\hline \multirow{2}{*}{\multicolumn{2}{|c|}{ Dietary patterns }} & \multicolumn{4}{|c|}{ Western } & \multicolumn{5}{|c|}{ Healthy } & \multicolumn{6}{|c|}{ Traditional } \\
\hline & & Q1 & Q2 & Q3 & Q4 & $p$ & Q1 & Q2 & Q3 & Q4 & $p$ & Q1 & Q2 & Q3 & Q4 & $\mathrm{p}$ \\
\hline n & & 155 & 156 & 156 & 155 & & 155 & 156 & 156 & 155 & & 155 & 156 & 156 & 155 & \\
\hline Age $(\text { mean })^{\dagger}$ & & 14.0 & 14.0 & 14.5 & 15.5 & $<.0001$ & 15.0 & 14.3 & 14.5 & 14.5 & 0.1218 & 14.1 & 14.1 & 15.0 & 15.2 & $<.0001$ \\
\hline \multicolumn{17}{|c|}{$\begin{array}{l}\text { Community size (number of subjects, } \\
\%)^{\ddagger}\end{array}$} \\
\hline \multicolumn{2}{|l|}{$<5000$ inhabitants } & 28.0 & 30.8 & 18.1 & 23.1 & & 29.7 & 33.1 & 21.1 & 16.2 & & 17.9 & 23.8 & 25.4 & 32.9 & \\
\hline \multicolumn{2}{|c|}{$5000-<100000$ inhabitants } & 18.9 & 23.9 & 25.9 & 31.3 & & 27.3 & 25.5 & 24.0 & 23.2 & & 25.1 & 28.0 & 25.5 & 21.4 & \\
\hline \multicolumn{2}{|l|}{$>100000$ inhabitants } & 24.2 & 22.1 & 25.2 & 28.6 & 0.1931 & 20.1 & 19.9 & 26.8 & 33.2 & 0.033 & 38.2 & 20.7 & 23.6 & 17.6 & 0.0079 \\
\hline \multicolumn{2}{|c|}{ Socioeconomic status $(3-21){ }^{\S \dagger}$} & 12.7 & 11.5 & 12.4 & 11.4 & 0.0341 & 11.2 & 12.0 & 12.4 & 12.4 & 0.0226 & 12.1 & 12.4 & 12.1 & 11.2 & 0.0988 \\
\hline \multicolumn{17}{|l|}{$\begin{array}{l}\text { Education (number of } \\
\text { subjects } \%)^{\ddagger}\end{array}$} \\
\hline \multicolumn{2}{|l|}{ Grammar school } & 33.5 & 21.7 & 25.9 & 18.9 & & 12.1 & 24.0 & 33.7 & 30.2 & & 30.2 & 28.9 & 22.1 & 18.7 & \\
\hline \multicolumn{2}{|l|}{ Secondary schooll } & 15.7 & 32.0 & 22.3 & 30.0 & & 33.1 & 26.2 & 18.4 & 22.3 & & 30.3 & 23.4 & 21.5 & 24.8 & \\
\hline \multicolumn{2}{|l|}{ Others } & 21.4 & 22.3 & 30.8 & 25.5 & 0.0008 & 28.1 & 27.0 & 16.1 & 28.7 & 0.0001 & 22.6 & 28.6 & 30.1 & 18.7 & 0.4305 \\
\hline \multicolumn{2}{|c|}{$\begin{array}{l}\text { Dietary supplement user (number of } \\
\text { subjects, } \%)^{ \pm \Uparrow}\end{array}$} & 16.4 & 23.4 & 26.7 & 33.6 & 0.4234 & 17.1 & 19.7 & 26.6 & 36.6 & 0.0109 & 24.7 & 23.8 & 24.5 & 27.0 & 0.6456 \\
\hline \multicolumn{17}{|c|}{$\begin{array}{l}\text { Joint family meals (number of subjects, } \\
\%)^{\ddagger}\end{array}$} \\
\hline \multirow[t]{2}{*}{ breakfast } & $\begin{array}{l}\text { at least three or } \\
\text { five times a } \\
\text { week }\end{array}$ & 29.2 & 30.8 & 21.2 & 18.8 & & 23.2 & 27.4 & 23.5 & 26.0 & & 23.3 & 24.2 & 24.4 & 28.2 & \\
\hline & $\begin{array}{l}\text { more seldom or } \\
\text { never }\end{array}$ & 19.0 & 21.2 & 25.8 & 33.9 & 0.0004 & 26.1 & 24.4 & 24.8 & 24.7 & 0.8159 & 29.8 & 25.6 & 25.7 & 18.9 & 0.1033 \\
\hline \multirow[t]{2}{*}{ lunch } & $\begin{array}{l}\text { at least three or } \\
\text { five times a } \\
\text { week }\end{array}$ & 24.9 & 27.1 & 23.8 & 24.2 & & 23.7 & 26.1 & 23.7 & 26.4 & & 28.4 & 23.1 & 26.2 & 22.3 & \\
\hline & $\begin{array}{l}\text { more seldom or } \\
\text { never }\end{array}$ & 19.6 & 21.4 & 24.7 & 34.4 & 0.0678 & 27.0 & 24.5 & 25.0 & 23.5 & 0.7651 & 26.9 & 27.4 & 24.1 & 21.6 & 0.7472 \\
\hline \multirow[t]{2}{*}{ dinner } & $\begin{array}{l}\text { at least three or } \\
\text { five times a } \\
\text { week }\end{array}$ & 24.3 & 25.3 & 24.0 & 26.5 & & 19.9 & 25.0 & 25.8 & 29.3 & & 28.5 & 25.2 & 22.8 & 23.5 & \\
\hline & $\begin{array}{l}\text { more seldom or } \\
\text { never }\end{array}$ & 18.2 & 22.8 & 24.9 & 34.0 & 0.2888 & 38.4 & 26.4 & 20.4 & 14.8 & $<.0001$ & 26.2 & 24.8 & 30.5 & 18.5 & $<.0001$ \\
\hline
\end{tabular}

Lunch at school (number of subjects, $\%)^{\ddagger}$

\begin{tabular}{|c|c|c|c|c|c|c|c|c|c|c|c|c|c|c|c|}
\hline $\begin{array}{l}\text { Five times a } \\
\text { week }\end{array}$ & 7.8 & 7.1 & 10.6 & 6.8 & & 7.3 & 8.0 & 7.4 & 9.7 & & 1.9 & 13.3 & 7.2 & 9.0 & \\
\hline $\begin{array}{l}\text { at least one or } \\
\text { two times a } \\
\text { week }\end{array}$ & 24.8 & 24.5 & 18.6 & 36.2 & & 23.1 & 23.3 & 21.5 & 35.3 & & 26.0 & 24.7 & 26.3 & 26.8 & \\
\hline $\begin{array}{l}\text { more seldom or } \\
\text { never }\end{array}$ & 67.5 & 68.4 & 70.8 & 57.1 & 0.3754 & 69.6 & 68.7 & 71.1 & 55.0 & 0.4794 & 72.1 & 62.0 & 66.5 & 64.2 & 0.2698 \\
\hline
\end{tabular}

Cooking skills (number of subjects, \%) $)^{\ddagger}$

Physical activity (hours per week) ${ }^{\dagger}$

Time spent watching TV a day ${ }^{\ddagger}$

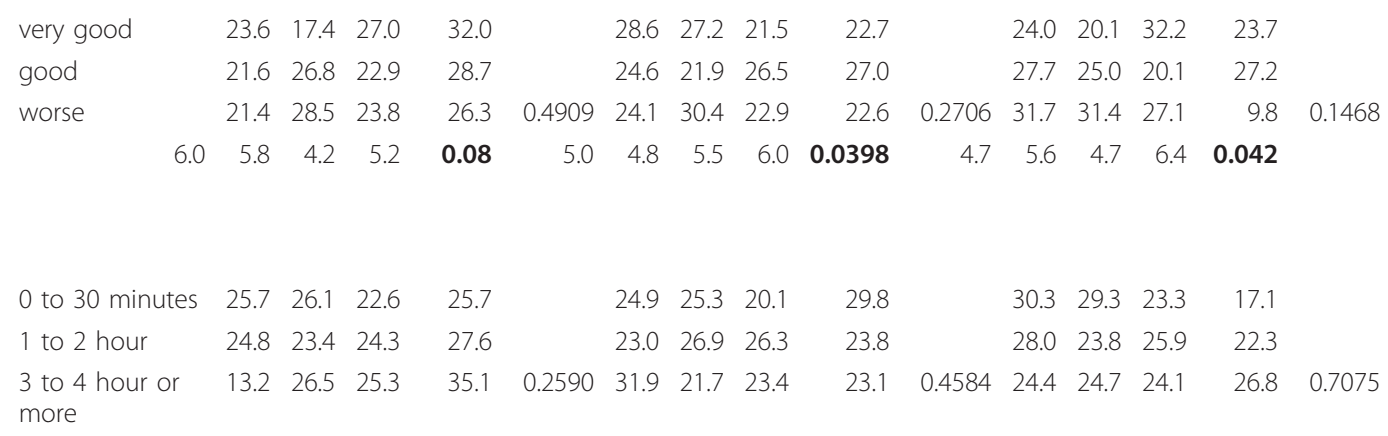


Table 2 Socio-demographic and behavioural sample characteristics of German boys according to quartiles of dietary pattern scores (Continued)

\begin{tabular}{lllllllllllllllll}
\hline Overweight adolescents & 21.3 & 22.5 & 29.9 & 26.3 & 0.7168 & 28.0 & 22.9 & 17.3 & 31.7 & 0.3934 & 36.6 & 19.6 & 20.4 & 23.4 & 0.2774
\end{tabular} (number of subjects,

$\%)^{\ddagger}$

${ }^{\dagger}$ test for trends

${ }^{\ddagger} X^{2}$ statistics

${ }^{\S}$ Index according to Winkler [33]

II Haupt- oder Realschule

" at least one time supplement use within a reference period of 4 weeks

Table 3 Socio-demographic and behavioural sample characteristics of German girls according to quartiles of dietary pattern scores

\begin{tabular}{|c|c|c|c|c|c|c|c|c|c|c|c|}
\hline \multirow{2}{*}{\multicolumn{2}{|c|}{ Dietary patterns }} & \multicolumn{4}{|c|}{ Healthy } & \multicolumn{6}{|c|}{ Traditional and Western } \\
\hline & & Q1 & Q2 & Q3 & Q4 & $p$ & Q1 & Q2 & Q3 & Q4 & $\bar{p}$ \\
\hline $\mathrm{n}$ & & 162 & 163 & 163 & 162 & & 162 & 163 & 163 & 162 & \\
\hline Age (me & & 14.6 & 14.3 & 14.6 & 14.8 & 0.2309 & 15.0 & 14.4 & 14.6 & 14.3 & 0.0108 \\
\hline \multicolumn{12}{|c|}{ Community size (number of subjects, $\%)^{\ddagger}$} \\
\hline$<50$ & abitants & 29.4 & 25.9 & 29.8 & 14.9 & & 29.6 & 20.3 & 22.9 & 27.2 & \\
\hline 5000 & 0000 inhabitants & 25.1 & 26.3 & 20.6 & 27.9 & & 24.5 & 26.1 & 25.8 & 23.7 & \\
\hline$>10$ & habitants & 22.0 & 21.7 & 22.4 & 33.9 & 0.0582 & 28.4 & 25.9 & 23.4 & 22.3 & 0.8168 \\
\hline Socioeco & status $(3-21)^{\S \dagger}$ & 11.5 & 11.0 & 12.8 & 11.4 & 0.4352 & 12.8 & 11.7 & 12.2 & 9.8 & $<.0001$ \\
\hline \multicolumn{12}{|c|}{ Education (number of subjects $\%)^{\ddagger}$} \\
\hline Gran & chool & 23.6 & 20.2 & 27.5 & 28.8 & & 31.9 & 23.4 & 27.7 & 17.0 & \\
\hline Seco & schooll & 27.0 & 30.5 & 19.5 & 23.0 & & 22.1 & 23.0 & 21.1 & 33.8 & \\
\hline Othe & & 28.9 & 24.4 & 17.4 & 29.3 & 0.1290 & 24.5 & 31.5 & 27.2 & 16.8 & 0.0019 \\
\hline Dietary & ment user (number of subjects, \%) & 19.3 & 22.4 & 23.2 & 35.1 & 0.1759 & 29.9 & 18.1 & 22.6 & 29.5 & 0.2568 \\
\hline \multicolumn{12}{|c|}{ Joint family meals (number of subjects, $\%)^{\ddagger}$} \\
\hline \multirow[t]{2}{*}{ breakfast } & at least three or five times a week & 23.7 & 25.5 & 27.4 & 23.5 & & 27.7 & 23.7 & 24.1 & 24.6 & \\
\hline & more seldom or never & 25.9 & 25.1 & 19.9 & 29.1 & 0.2244 & 25.5 & 25.7 & 24.9 & 24.0 & 0.9405 \\
\hline \multirow[t]{2}{*}{ lunch } & at least three or five times a week & 23.9 & 26.9 & 21.6 & 27.6 & & 26.3 & 26.2 & 23.2 & 24.3 & \\
\hline & more seldom or never & 26.6 & 23.3 & 23.4 & 26.8 & 0.7373 & 26.1 & 23.5 & 26.4 & 24.1 & 0.8447 \\
\hline \multirow[t]{2}{*}{ dinner } & at least three or five times a week & 24.5 & 26.8 & 21.7 & 27.1 & & 26.4 & 24.1 & 25.9 & 23.6 & \\
\hline & more seldom or never & 26.2 & 21.6 & 24.7 & 27.6 & 0.6814 & 26.4 & 26.6 & 21.4 & 25.6 & 0.7490 \\
\hline \multicolumn{12}{|c|}{ Lunch at school (number of subjects, \%) } \\
\hline & Five times a week & 5.0 & 6.6 & 6.1 & 3.5 & & 2.0 & 6.7 & 5.0 & 7.9 & \\
\hline & at least one or two times a week & 14.0 & 27.4 & 16.8 & 9.1 & & 17.2 & 19.3 & 13.7 & 14.6 & \\
\hline & more seldom or never & 81.1 & 66.0 & 77.1 & 87.4 & 0.0531 & 80.8 & 74.0 & 81.3 & 77.5 & 0.5885 \\
\hline \multicolumn{12}{|c|}{ Cooking skills (number of subjects, $\%)^{\ddagger}$} \\
\hline & very good & 22.8 & 24.7 & 19.8 & 32.8 & & 29.8 & 21.6 & 22.6 & 26.1 & \\
\hline & good & 26.3 & 24.1 & 25.2 & 24.4 & & 24.2 & 26.1 & 26.1 & 23.6 & \\
\hline & worse & 28.4 & 29.8 & 20.0 & 21.8 & 0.1413 & 26.4 & 28.2 & 24.5 & 20.9 & 0.3977 \\
\hline Physical & $y$ (hours per week) $^{\dagger}$ & 3.5 & 4.2 & 3.6 & 3.2 & 0.2021 & 4.3 & 3.3 & 3.4 & 3.5 & 0.1801 \\
\hline \multicolumn{12}{|c|}{ Time spent watching TV a day ${ }^{\ddagger}$} \\
\hline & 0 to 30 minutes & 20.9 & 22.5 & 27.2 & 29.3 & & 35.1 & 25.3 & 20.1 & 19.6 & \\
\hline & 1 to 2 hour & 24.4 & 27.1 & 22.4 & 26.2 & & 27.0 & 25.3 & 26.1 & 21.6 & \\
\hline & 3 to 4 hour or more & 32.7 & 21.1 & 19.0 & 27.2 & 0.4633 & 16.0 & 22.4 & 24.9 & 36.7 & 0.0144 \\
\hline Overwei & olescents (number of subjects, $\%)^{\ddagger}$ & 24.1 & 31.8 & 26.0 & 18.1 & 0.3941 & 31.5 & 25.6 & 22.8 & 20.1 & 0.7781 \\
\hline
\end{tabular}

\footnotetext{
${ }^{\dagger}$ test for trends

${ }^{\ddagger} X^{2}$ statistics

${ }^{\S}$ Index according to Winkler [33]

I Haupt- oder Realschule

" at least one time supplement use within a reference period of 4 weeks
} 
Table 4 Mean daily energy and nutrient density* according to quartiles of the dietary pattern scores identified among German boys

\begin{tabular}{|c|c|c|c|c|c|c|c|c|c|c|c|c|c|c|c|}
\hline & \multicolumn{4}{|c|}{ Western pattern } & \multicolumn{5}{|c|}{ Healthy pattern } & \multicolumn{6}{|c|}{ Traditional pattern } \\
\hline & Q1 & Q2 & Q3 & Q4 & $\begin{array}{l}\mathrm{P} \text { for } \\
\text { trend }\end{array}$ & Q1 & Q2 & Q3 & Q4 & $\begin{array}{l}\mathrm{P} \text { for } \\
\text { trend }\end{array}$ & Q1 & Q2 & Q3 & Q4 & $\begin{array}{l}P \text { for } \\
\text { trend }\end{array}$ \\
\hline Energy intake (MJ) & 11.0 & 11.2 & 12.1 & 16.5 & $<.0001$ & 12.7 & 11.4 & 12.7 & 14.9 & $<.0001$ & 10.2 & 11.3 & 14 & 16.8 & $<.0001$ \\
\hline \multicolumn{16}{|l|}{$\%$ of energy } \\
\hline Total fat & 32.5 & 34.3 & 34.1 & 33.8 & 0.283 & 33.6 & 34.3 & 33.1 & 33.8 & 0.955 & 31.8 & 32.9 & 34.7 & 35.7 & $<.0001$ \\
\hline $\begin{array}{l}\text { Saturated fatty } \\
\text { acids (SFA) }\end{array}$ & 14.0 & 15.0 & 14.5 & 13.8 & 0.1016 & 14.4 & 14.9 & 14.1 & 14.0 & 0.1629 & 13.3 & 14.0 & 14.9 & 15.4 & $<.0001$ \\
\hline $\begin{array}{l}\text { Unsaturated fatty } \\
\text { acids }\end{array}$ & 1.2 & 11.9 & 12.1 & 12.1 & 7 & 11.9 & 12.1 & 11.6 & 11.8 & 7 & 11.1 & 11.7 & 12.1 & 12.7 & $<$ \\
\hline $\begin{array}{l}\text { Polyunsaturated } \\
\text { fatty acids (PUFA) }\end{array}$ & 4.7 & 4.8 & 4.9 & 5.0 & 0.1016 & 4.6 & 4.7 & 4.8 & 5.3 & .001 & 4.9 & 4.7 & 4.9 & 5.0 & 0.548 \\
\hline Protein & 13.7 & 13.4 & 13.9 & 13.8 & 0. & 13.0 & 13.6 & 13.9 & 14.3 & $<$ & 13.7 & 13.6 & 13.7 & 13.9 & 0.511 \\
\hline $\begin{array}{l}\text { Total } \\
\text { Carbohydrates }\end{array}$ & 52.5 & 50.9 & 50.4 & 49.4 & 0.0003 & 50.9 & 50.4 & 51.2 & 50.4 & 0.699 & 53.0 & 52.0 & 49.2 & 48.2 & $<.0001$ \\
\hline Monosaccharide & 11.3 & 11.1 & 11.6 & 11.2 & 0.9334 & 11.9 & 10.9 & 11.2 & 11.1 & 0.4272 & 11.8 & 11.8 & 10.9 & 10.5 & 0.0213 \\
\hline Disaccharide & 14.7 & 16.0 & 15.2 & 15.1 & 0.9302 & 16.2 & 15.3 & 15.3 & 14.3 & 0.00 & 15.6 & 15.8 & 15.1 & 14.5 & 0.068 \\
\hline $\begin{array}{l}\text { Polysaccharide } \\
\text { (absorbable) }\end{array}$ & 26.1 & 23.7 & 23.5 & 23.3 & 0.0016 & 23.1 & 24.1 & 24.5 & 24.5 & 0.0785 & 25.7 & 24.1 & 23.1 & 23.0 & 0.0004 \\
\hline Alcohol & 0.5 & 0.4 & 0.8 & 1.9 & $<.0001$ & 1.6 & 0.8 & 0.9 & 0.6 & 0.001 & 0.5 & 0.6 & 1.5 & 1.4 & 0.001 \\
\hline \multicolumn{16}{|l|}{$\begin{array}{l}\text { Energy and nutrient } \\
\text { density }\end{array}$} \\
\hline Energy $(\mathrm{kJ} / 100 \mathrm{~g})^{\dagger}$ & 604.4 & 656.6 & 711.7 & 725.3 & $<.0001$ & 762.4 & 692.7 & 656.1 & 598.7 & $<.0001$ & 657.1 & 679 & 675.1 & 707.5 & 0.001 \\
\hline le) (g/MJ) & 3.0 & 2.3 & 2.2 & 1.9 & $<.0001$ & 1.8 & 2.2 & 2.5 & 2.7 & $<.0001$ & 2.4 & 2.4 & 2.2 & 2.2 & 0.021 \\
\hline Vitamin A ( $\mu \mathrm{g} / \mathrm{MJ})$ & 144.4 & 133.7 & 120.5 & 113.4 & $<.0001$ & 106.6 & 118.0 & 136.0 & 148.4 & $<.0001$ & 119.0 & 127.1 & 128.8 & 134.7 & 0.05 \\
\hline $\begin{array}{l}\text { Beta-Carotene ( } \mu \mathrm{g} / \\
\text { MJ) }\end{array}$ & 471.6 & 403.9 & 373.9 & 320.9 & $<.0001$ & 241.1 & 332.7 & 450.0 & 533.4 & $<.0001$ & 408.0 & 397.9 & 368.9 & 371.5 & 0.268 \\
\hline Vitamin C (mg/MJ) & 18.9 & 16.7 & 14.0 & 14.4 & 0.009 & 12.0 & 15.5 & 16.7 & 19.5 & $<.0001$ & 15.8 & 15.8 & 16.3 & 15.4 & 0.0 \\
\hline $\operatorname{tamin} \mathrm{D}(\mu \mathrm{g} / \mathrm{MJ})$ & 0.3 & 0.2 & 0.2 & 0.2 & 0.006 & 0.2 & 0.2 & 0.2 & 0.3 & 0.015 & 0.2 & 0.2 & 0.2 & 0.3 & 0.00 \\
\hline Vitamin E ( $\mu \mathrm{g} / \mathrm{MJ})$ & 1637.4 & 1521.5 & 1428.3 & 1296.6 & $<.0001$ & 1271.4 & 1392.3 & 1559.8 & 1623.0 & $<.0001$ & 1550.4 & 1471.6 & 1386.9 & 1413.7 & 0.077 \\
\hline Vitamin K ( $\mu \mathrm{g} / \mathrm{MJ})$ & 34.3 & 29.3 & 28.6 & 27.1 & 0.0001 & 21.6 & 27.8 & 31.2 & 38.1 & $<.0001$ & 30.3 & 29.4 & 29.8 & 28.6 & 0.297 \\
\hline Vitamin $B_{1}(\mu \mathrm{g} / \mathrm{MJ})$ & 208.3 & 187.4 & 179.0 & 160.6 & $<.0001$ & 166.4 & 181.4 & 194.1 & 187.7 & 0.042 & 180.3 & 184.7 & 175.1 & 189.7 & 0.496 \\
\hline Vitamin $B_{2}(\mu \mathrm{g} / \mathrm{MJ})$ & 242.0 & 217.4 & 190.7 & 180.6 & $<.0001$ & 193.7 & 203.2 & 215.5 & 211.0 & 0.124 & 210.4 & 202.4 & 200.9 & 208.8 & 0.88 \\
\hline Niacin $(\mu \mathrm{g} / \mathrm{MJ})^{\ddagger}$ & 3464.1 & 3285.9 & 3300.0 & 3242.6 & 0.184 & 3052.5 & 3200.5 & 3528.8 & 3497.9 & 0.0003 & 3349.2 & 3288 & 3240 & 3391.8 & 0.808 \\
\hline Vitamin $B_{5}(\mu \mathrm{g} / \mathrm{MJ})$ & 786.2 & 701.2 & 644.1 & 594.2 & $<.0001$ & 593.0 & 654.5 & 733.6 & 723.6 & 0.001 & 694.4 & 681.1 & 641.8 & 681.6 & 0.600 \\
\hline Vitamin $B_{6}(\mu \mathrm{g} / \mathrm{MJ})$ & 267.3 & 245.0 & 227.5 & 218.7 & 0.006 & 214.5 & 222.8 & 262.5 & 253.9 & 0.002 & 243.0 & 237.7 & 226.6 & 245.2 & 0.978 \\
\hline Biotin $(\mu \mathrm{g} / \mathrm{MJ})$ & 9.3 & 8.0 & 7.5 & 6.3 & 0.002 & 6.3 & 7.6 & 8.7 & 8.1 & 0.040 & 8.3 & 8.0 & 6.9 & 7.5 & 0.21 \\
\hline Folate $(\mu \mathrm{g} / \mathrm{MJ})$ & 35.9 & 29.8 & 27.5 & 26.8 & $<.0001$ & 26.5 & 27.5 & 31.7 & 33.3 & 0.0002 & 31.2 & 29.1 & 28.8 & 29.5 & 0.431 \\
\hline $\begin{array}{l}\text { Vitamin } B_{12}(\mu \mathrm{g} / \\
\mathrm{MJ})\end{array}$ & 0.6 & 0.6 & 0.5 & 0.5 & 0.419 & 0.5 & 0.5 & 0.6 & 0.5 & 0.999 & 0.5 & 0.5 & 0.6 & 0.6 & $<.0001$ \\
\hline Calcium (mg/MJ) & 141.6 & 128.2 & 112.4 & 101.4 & $<.0001$ & 108.5 & 123.9 & 126.2 & 120.0 & 0.069 & 125 & 117.9 & 118.6 & 115.6 & 0.10 \\
\hline $\begin{array}{l}\text { Magnesium (mg/ } \\
\text { MJ) }\end{array}$ & 50.4 & 42.8 & 41.3 & 37.2 & $<.0001$ & 36.0 & 43.0 & 45.5 & 45.8 & $<.0001$ & 45.4 & 43.0 & 41.0 & 40.1 & 0.0002 \\
\hline Iron ( $\mu \mathrm{g} / \mathrm{MJ})$ & 1646.2 & 1419.0 & 1427.5 & 1386.5 & $<.0001$ & 1333.2 & 1412.9 & 1521.3 & 1586.1 & $<.0001$ & 1511.3 & 1476.0 & 1425.0 & 1426.1 & 0.040 \\
\hline
\end{tabular}

*Does not include nutrient intake from dietary supplements

${ }^{+}$Foods without beverages

₹ Niacin equivalent

'western' and 'healthy' dietary patterns among boys and the 'traditional and western' pattern among girls were correlated to socioeconomic status.

The identification of dietary patterns in a representative sample of the adolescent population and their relation to socioeconomic status, nutritional behaviour and nutrient intake has been rarely examined. Empirical evaluated dietary patterns are specific for the examined study population and reflect culturally influenced eating habits. Furthermore, studies used different methods e. g. 
Table 5 Mean daily energy and nutrient density* according to quartiles of the dietary pattern scores identified among German girls

\begin{tabular}{|c|c|c|c|c|c|c|c|c|c|c|}
\hline & \multicolumn{4}{|c|}{ Healthy pattern } & \multicolumn{6}{|c|}{ Traditional and western pattern } \\
\hline & Q1 & Q2 & Q3 & Q4 & $P$ for trend & Q1 & Q2 & Q3 & Q4 & $P$ for trend \\
\hline Energy intake (MJ) & 9.2 & 8.9 & 9.6 & 11.0 & $<.0001$ & 7.3 & 8.5 & 10.0 & 13.3 & $<.0001$ \\
\hline \multicolumn{11}{|l|}{$\%$ of energy } \\
\hline Total fat & 32.4 & 32.3 & 31.8 & 32.2 & 0.864 & 30.2 & 31.2 & 32.9 & 34.6 & $<.0001$ \\
\hline Saturated fatty acids (SFA) & 14.2 & 14.0 & 13.8 & 13.3 & 0.031 & 12.6 & 13.6 & 14.3 & 14.8 & $<.0001$ \\
\hline Unsaturated fatty acids & 11.4 & 11.1 & 10.8 & 10.7 & 0.0309 & 10.0 & 10.6 & 11.3 & 12.2 & $<.0001$ \\
\hline Polyunsaturated fatty acids (PUFA) & 4.4 & 4.7 & 4.8 & 5.7 & 0.0026 & 5.3 & 4.6 & 4.8 & 4.9 & 0.5288 \\
\hline Protein & 12.4 & 13.0 & 13.0 & 13.6 & 0.001 & 13.3 & 12.8 & 12.8 & 13.1 & 0.593 \\
\hline Total Carbohydrates & 53.4 & 53.3 & 53.4 & 52.5 & 0.319 & 54.6 & 54.2 & 52.6 & 50.8 & $<.0001$ \\
\hline Monosaccharide & 13.4 & 12.1 & 12.2 & 12.5 & 0.4261 & 13.7 & 12.6 & 12.0 & 11.9 & 0.0251 \\
\hline Disaccharide & 16.6 & 17.2 & 15.6 & 15.8 & 0.0674 & 15.1 & 17.2 & 16.5 & 16.5 & 0.1092 \\
\hline Polysaccharide (absorbable) & 23.5 & 23.9 & 25.2 & 24.0 & 0.4346 & 25.1 & 24.4 & 24.0 & 22.9 & 0.0126 \\
\hline Alcohol & 0.9 & 0.5 & 0.8 & 0.6 & 0.293 & 0.9 & 0.7 & 0.7 & 0.5 & 0.011 \\
\hline \multicolumn{11}{|l|}{ Energy and nutrient density } \\
\hline Energy $(\mathrm{kJ} / 100 \mathrm{~g})^{\dagger}$ & 695.2 & 630.3 & 589.8 & 540.2 & $<.0001$ & 547.3 & 601.9 & 635.4 & 673.8 & $<.0001$ \\
\hline Fibre (not absorbable) (g/MJ) & 2.2 & 2.6 & 3.0 & 3.1 & $<.0001$ & 3.4 & 2.7 & 2.4 & 2.2 & $<.0001$ \\
\hline Vitamin A ( $\mu \mathrm{g} / \mathrm{MJ})$ & 138.7 & 147.7 & 165.9 & 180.8 & $<.0001$ & 191.0 & 148.6 & 146.2 & 145.8 & 0.0003 \\
\hline Beta-Carotene ( $\mu \mathrm{g} / \mathrm{MJ})$ & 402.9 & 500.6 & 603.4 & 702.5 & $<.0001$ & 747.3 & 532.3 & 461.8 & 459.0 & $<.0001$ \\
\hline Vitamin C (mg/MJ) & 18.0 & 20.1 & 22.5 & 23.9 & 0.0002 & 26.4 & 21.7 & 17.6 & 18.4 & $<.0001$ \\
\hline Vitamin D $(\mu \mathrm{g} / \mathrm{MJ})$ & 0.2 & 0.2 & 0.2 & 0.3 & 0.001 & 0.2 & 0.2 & 0.2 & 0.2 & 0.735 \\
\hline Vitamin E ( $\mu \mathrm{g} / \mathrm{MJ})$ & 1573.8 & 1683.0 & 1674.1 & 1893.1 & 0.078 & 2078.0 & 1618.9 & 1543.4 & 1573.0 & 0.008 \\
\hline Vitamin K ( $\mu \mathrm{g} / \mathrm{MJ})$ & 25.3 & 31.2 & 38.8 & 46.0 & $<.0001$ & 41.7 & 35.7 & 32.6 & 31.3 & $<.0001$ \\
\hline Vitamin $B_{1}(\mu \mathrm{g} / \mathrm{MJ})$ & 191.5 & 193.8 & 179.0 & 176.3 & 0.229 & 206.3 & 176.0 & 171.8 & 185.0 & 0.386 \\
\hline Vitamin $B_{2}(\mu \mathrm{g} / \mathrm{MJ})$ & 225.3 & 232.0 & 212.9 & 209.0 & 0.222 & 246.0 & 211.5 & 208.9 & 210.7 & 0.203 \\
\hline Niacin $(\mu \mathrm{g} / \mathrm{MJ})^{\ddagger}$ & 3200.0 & 3373.0 & 3249.8 & 3366.4 & 0.547 & 3653.4 & 3142.5 & 3075.1 & 3305.5 & 0.280 \\
\hline Vitamin $B_{5}(\mu \mathrm{g} / \mathrm{MJ})$ & 728.6 & 758.2 & 727.6 & 731.8 & 0.905 & 855.9 & 705.1 & 673.1 & 703.8 & 0.129 \\
\hline Vitamin $B_{6}(\mu \mathrm{g} / \mathrm{MJ})$ & 244.6 & 254.5 & 247.4 & 248.8 & 0.956 & 288.1 & 236.8 & 225.3 & 242.6 & 0.177 \\
\hline Biotin ( $\mu \mathrm{g} / \mathrm{MJ})$ & 9.1 & 9.4 & 8.3 & 7.8 & 0.251 & 10.7 & 7.9 & 7.6 & 8.3 & 0.284 \\
\hline Folate ( $\mu \mathrm{g} / \mathrm{MJ})$ & 31.3 & 34.1 & 34.3 & 36.6 & 0.040 & 40.6 & 33.3 & 31.3 & 30.8 & 0.0028 \\
\hline Vitamin $B_{12}(\mu \mathrm{g} / \mathrm{MJ})$ & 0.5 & 0.5 & 0.5 & 0.5 & 0.002 & 0.5 & 0.5 & 0.5 & 0.5 & 0.275 \\
\hline Calcium (mg/MJ) & 123.2 & 136.7 & 145.0 & 141.4 & 0.006 & 173.0 & 133.3 & 130.5 & 105.7 & $<.0001$ \\
\hline Magnesium (mg/MJ) & 41.4 & 46.4 & 50.9 & 52.0 & $<.0001$ & 60.9 & 46.5 & 44.3 & 37.7 & $<.0001$ \\
\hline Iron ( $\mu \mathrm{g} / \mathrm{MJ})$ & 1427.2 & 1518.7 & 1584.1 & 1675.0 & $<.0001$ & 1713.9 & 1560.2 & 1482.6 & 1440.4 & $<.0001$ \\
\hline
\end{tabular}

*Does not include nutrient intake from dietary supplements

${ }^{\dagger}$ Foods without beverages

${ }^{\ddagger}$ Niacin equivalent

for food grouping. Therefore, deviations between dietary pattern compositions are obvious. Nevertheless, the patterns found among German adolescents were, to some extent, similar to those found in previous studies in this age group in other countries. Comparison of dietary patterns among adolescents between different countries can give useful information on similarities in food consumption behaviour between different populations. For such comparison however cultural and economic conditions should be similar so that it is likely that the food supply is similar. If similar dietary patterns are found in such countries, it could be interesting to obtain further information concerning the associations between patterns and health in this age group.
Our 'western' pattern was partly comparable to the 'western' patterns found among adolescents in other countries e. g. in the Western Australian Pregnancy Cohort Study (Raine Study) [40] and in the Korean Nutrition Health and Nutrition Examination Survey (KNHANES) [29] and also to the 'high fat and sugar' pattern found in a representative sample of adolescents in the 1995 Australian National Nutrition Survey [27]. All these patterns were characterized by pizza, hamburger, soft drinks and meat or meat products. In contradiction to our study, alcohol consumption was not analysed in those studies. In Germany, we observed that adolescents already consume relevant amounts of alcoholic drinks [41]. 
Our 'healthy' patterns were to some extent comparable to other 'healthy' patterns found among adolescents e. g. in a population based sample of Spanish adolescents, and in samples of adolescents in Finland (Cardiovascular Risk in Young Finns Study), Japan (Japanese female dietetic course students), and Australia (Raine Study) $[4,18,23,40]$ and to the 'fruit, salad, cereals, and fish pattern' found in the 1995 Australian National Nutrition Survey [27].

Our findings on the association between dietary pattern and nutrient intake were especially similar to results of the 1995 Australian National Nutrition Survey [27]. Adolescents in Australia with a higher score of the 'fruit, salad, cereals, and fish' pattern had a higher energy-adjusted intake of dietary fibre, beta carotene, folate, vitamin $\mathrm{C}$ and protein similar as German adolescents with higher scores of the 'healthy' patterns. The 'high fat and sugar' pattern was associated with a lower energy adjusted intake of dietary fibre, folate and iron [27].

Among German adolescents, despite the high intakes of meat in the 'western', 'traditional' and 'traditional and western' patterns, iron density decreased with increasing scores of these patterns, whereas iron density increased with increasing scores of the 'healthy' patterns. This can be explained by the fact that meat and processed meats are less important sources of iron than bread, juices, vegetables, fruits and breakfast cereals among German adolescents [38]. However, this does not consider differences in bioavailability of iron between animal and vegetarian foods. Furthermore, white bread, a characteristic component of the 'traditional' pattern, has lower iron content than whole grain bread.

Most former studies [23,27,40] determined dietary patterns for boys and girls together. Among German adolescents, we found different dietary patterns between boys and girls. Even between the 'healthy' dietary patterns, differences concerning the food group loadings are notable. Further differences between boys and girls were found. Firstly, for boys the most predominant dietary pattern was the 'western' pattern, among girls the 'healthy'. Second, among boys many associations between the 'healthy' dietary pattern and socioeconomic or behavioural factors (e. g. physical activity, frequency of joined family dinner) were found. Among girls there was no association between socioeconomic or behavioural factors and the 'healthy' dietary pattern. Thirdly, the two predominant dietary patterns found among German girls explained only $13.2 \%$ of variance in food group intake, while among German boys, the three predominant dietary patterns explained $18.1 \%$ of variance. This may indicate that there is more individual diversity within the diet of girls or that boys have more often similar food preferences. Fourthly, particularly notable among German boys was the increasing age from the lowest to the highest quartile of the 'western' pattern. Among girls, with increasing scores of the 'traditional and western' pattern age was decreasing. The present study used a cross sectional design. Thus, we are not able to evaluate long term changes. But it may be assumed, that boys change their eating behaviours during adolescence toward a less favourable dietary pattern, whereas girls do not.

Among U.S. middle and high school students in Minnesota (Project EAT) [14] and students in Vyronas region, Athens [21] high scores of 'take away food' or 'fast food' patterns were associated with increasing age among both sexes.

Previous studies investigated the relationship between dietary patterns and socioeconomic parameters. In a representative sample of adolescents in Australia and among Greece students, no association was found $[21,27]$. In a German study, there was no association between clusters of fat intake patterns and mother's educational background [42]. In Australia (Raine Study), Finland (Cardiovascular Risk in Young Finns Study), and Scotland (The Survey of Sugar Intake among Children in Scotland), the 'healthy' or 'vegetables' patterns were associated with higher education of the mother [40], both parents [4] or the parent who mainly provides the food [25]. The 'western' pattern in the Australian Rain study and the 'traditional' pattern in Finland (Cardiovascular Risk in Young Finns Study) were associated with lower educational background. Furthermore, in Scotland (The Survey of Sugar Intake among Children in Scotland), the 'vegetables' pattern was associated with higher socioeconomic status and higher household income [25] and among adolescents of the Balearic Islands higher scores of the Mediterranean pattern were associated with higher parental socio-economic status among girls [24].

With increasing 'healthy' pattern scores, the percentages of boys taking dietary supplements increased. Among girls, this increase was not significant. Previous studies in Japan (Japanese female dietetic course students) [43] and Finland (Cardiovascular Risk in Young Finns Study) [4] found an increasing percentage of supplement users with increasing scores of healthy dietary patterns among both sexes.

In Finland (Cardiovascular Risk in Young Finns Study) and Japan (Japanese female dietetic course students), 'traditional' dietary patterns were found more often in rural areas $[4,18]$, whereas a 'healthy' pattern was observed more often in urban areas [4], which follows our results. Dietary patterns are very likely influenced by local food supply. In rural areas of Germany there are less fast food and non-traditional restaurants compared to urban areas. Maybe therefore, boys living 
in rural areas more often follow a traditional German diet.

Other studies have described an association between a higher level of physical activity and higher adherence to healthier dietary patterns $[21,23,44]$, like among boys in our study. Conversely, with increasing hours of watching television, a higher adherence to less healthy dietary patterns (e. g. 'snacky' or 'western'), similar to the association found among German girls with higher scores of the 'traditional and western' pattern in our study, was also previously observed $[21,24,25,40]$.

We also used energy-adjusted dietary pattern scores [45] (data not presented). This did not essentially change the results concerning the association between dietary pattern scores and socioeconomic and lifestyle characteristics.

In our study, no association between dietary pattern scores and overweight was found. Only few studies have previously investigated the association between dietary patterns and BMI among adolescents. These studies came to different results. In a German study, BMI showed no association to fat intake patterns within a longitudinal analysis [42]. A study in Scotland also found no association between dietary patterns and BMI [25]. Another study observed a lower BMI among those with a healthier dietary pattern and a higher BMI among those with a western dietary pattern [43]. One study even found a higher BMI among persons with a healthier nutrition [46].

One reason for the different results may be that overweight persons who attempt to lose weight tend to confound the relationship between nutrition and BMI [46]. Furthermore, obese people tend to underreport fatty foods and foods rich in carbohydrates [47]. Besides, it is difficult to detect minor overconsumption of energy in epidemiological studies that track the development of obesity over long periods [42] and overweight is primarily controlled by energy balance. Another source of error may be the bias of self-reported body weight and height, which often differ from measured figures [48]. In a subsample of KiGGS, validity of self-reported height and weight among 11- to 17-year-old adolescents was assessed. BMI values calculated from self-reported weight and height were lower than those calculated from measured values among both sexes [49]. Thus, we probably underestimate BMI in our study. However, standardized anthropometric measurements were not feasible due to the nature of household visits and interviews taken place in study vans.

Further analysis concerning dietary patterns and BMI were conducted while excluding low energy reporters (about 10\% of girls and 7\% of boys) [50]. This did not change the results essentially.

Strengths of this study include the utilization of representative population-based data and the comprehensive nutrition interview, which documented food consumption during a period of four weeks, as well as the inclusion of data on nutrition behaviour, lifestyle habits and socioeconomic background.

A limitation of our study is the cross-sectional design, which allows no statements concerning causation.

Potential limitations of the interview-based dietary assessment methods in general are underreporting of usual intake and invalid reporting due to memory gaps and social desirability. DISHES was only validated for adults but in a recent study among adolescents aged 12 to 17 years it showed fair to moderate ranking validity with food group intake assessed with a FFQ [51]. In addition, a pretest on feasibility of the use of DISHES in the age group of 12 to 17 years was conducted, which indicated no particular problems for conducting DISHES in this age group. Furthermore, most interviews where carried out at home of the participants, which gave the opportunity to get additional information from the parents (e. g. concerning name of meals, kind of meat).

Another limitation of the study was the self-reported physical activity which may be affected by misreporting, e. g. overreporting influenced by social desirability [52]. However, within the setting of this survey, more objective methods to determine physical activity would be too time-consuming and expensive and where therefore not feasible.

For children and adolescents with a migration background, a higher proportion of unreachable addresses and non-respondents were expected. Thus an oversampling of this population group was performed in KiGGS. Furthermore, invitation letters, information material and questionnaires were translated into six languages [31]. However, for the dietary assessment in EsKiMo, certain basic German language skills were required. Thus, the proportion of participants with a migration background in EsKiMo was somewhat lower than in KiGGS. However, $6.8 \%$ of the EsKiMo participants had a one-side and $11.3 \%$ a two-side migration background (unweighted percent). Nevertheless, separate analysis concerning migration background was not reasonable in EsKiMo because of a relatively small sample size which included only 65 boys and 79 girls with a migration background which came from several countries.

Principal component analysis is generally exposed to the limitation of some subjectivity, particularly when grouping the food items, selecting the method of factor rotation, defining the number of patterns to be retained and labelling of the factors [53]. To enable comparability with other studies, we used criteria similar to those reported by other dietary pattern analyses $[14,21]$. In addition, we tested a further version of food grouping with 32 food groups instead of 48 . This led to very 
similar results concerning the number of principal components to be retained and the food groups with high loadings within patterns. Correlation coefficients between pattern scores determined with 48 food groups and those determined with 32 food groups ranged between 0.93 and 0.97 . McCann also noted that food classification method affected neither the number nor character of the identified patterns [54].

Dietary patterns derived using principal component analysis generally tend to account for only a small amount of the total variance of diet [55]. The variance explained in the present study was similar to a study among 12 to 17 year-old Scottish adolescents, in which 3 dietary patterns based on 141 food groups accounted for $14.4 \%$ of variance among boys and $15.1 \%$ among girls [25]. A slightly higher variance than in our study was observed among 12 to 18 year-old Australian adolescents, in which 3 dietary patterns based on 86 food groups accounted for $21.7 \%$ of the variance in the data [27].

\section{Conclusions}

In conclusion, we detected three distinct dietary patterns among German boys and two among German girls. Dietary patterns were associated with differences in nutrient intake, socioeconomic status and lifestyle characteristics. Higher scores for unhealthier dietary patterns (with higher consumption of take away foods, meat, confectionary and soft drinks, higher energy density, higher percent of energy from unsaturated fatty acids, lower percent of energy from carbohydrates and lower nutrient densities of several vitamins and minerals) are observed more often among 16- to 17-years old boys and adolescents with lower SES. Therefore, nutritional interventions should try to focus more on adolescents with lower SES and boys in general.

\section{Abbreviations \\ SES: Socioeconomic status; PA: Physical activity; SFA: Saturated fatty acids; PUFA: Polyunsaturated fatty acids.}

\section{Acknowledgements}

This study was supported by the German Research Foundation (RO 2506/71). KiGGS was funded by the German Ministry of Health, the Ministry of Education and Research and the Robert Koch Institute. EskiMo was funded by the German Federal Ministry of Food, Agriculture, and Consumer Protection. We would like to thank the families who participated in KiGGS and EsKiMo.

\footnotetext{
Author details

'Marketing and Consumer Research, Technische Universität München, Alte Akademie 16, 85354 Freising, Germany. ${ }^{2}$ Department of Epidemiology and Health Reporting, Robert Koch Institute, Nordufer 20, 13353 Berlin, Germany. ${ }^{3}$ Department Molecular Epidemiology, German Institute of Human Nutrition, Arthur-Scheunert-Allee 114-116, 14558 Nuthetal, Germany. ${ }^{4}$ Department of Food Economics and Consumption Studies, Christian-Albrechts-Universität Kiel, Olshausenstraße 40, 24098 Kiel, Germany.
}

\section{Authors' contributions}

GBMM designed and managed EsKiMo; AR managed the field work of EsKiMo; GBMM, ST, JR, MBS, AR designed and wrote the study proposal for the pattern analysis; AR conducted the presented analysis and drafted the manuscript; $\mathrm{CH}$ and MBS assisted with statistical analysis and interpretation of the results; GBMM, JR, ST contributed to the interpretation of the results and the writing of the manuscript. All the authors were involved in the critical revision of the manuscript for important intellectual content.

\section{Competing interests}

The authors declare that they have no competing interests.

Received: 21 October 2011 Accepted: 22 March 2012

Published: 22 March 2012

\section{References}

1. Rogol AD, Roemmich JN, Clark PA: Growth at puberty. J Adolesc Health 2002, 31:192-200.

2. Birch $L L$, Fisher JO: Development of eating behaviors among children and adolescents. Pediatrics 1998, 101:539-549.

3. Spear BA: Adolescent growth and development. J Am Diet Assoc 2002, 102:S23-S29.

4. Mikkila V, Rasanen L, Raitakari OT, Pietinen P, Viikari J: Consistent dietary patterns identified from childhood to adulthood: the cardiovascular risk in Young Finns Study. Br J Nutr 2005, 93:923-931.

5. Lake AA, Mathers JC, Rugg-Gunn AJ, Adamson AJ: Longitudinal change in food habits between adolescence (11-12 years) and adulthood (32-33 years): the ASH30 Study. J Public Health (Oxf) 2006, 28:10-16.

6. Lien N, Lytle LA, Klepp KI: Stability in consumption of fruit, vegetables, and sugary foods in a cohort from age 14 to age 21. Prev Med 2001, 33:217-226.

7. Kelder SH, Perry CL, Klepp KI, Lytle LL: Longitudinal tracking of adolescent smoking, physical activity, and food choice behaviors. Am J Public Health 1994, 84:1121-1126.

8. Tercyak KP, Tyc VL: Opportunities and challenges in the prevention and control of cancer and other chronic diseases: children's diet and nutrition and weight and physical activity. J Pediatr Psychol 2006, 31:750-763.

9. Law M: Dietary fat and adult diseases and the implications for childhood nutrition: an epidemiologic approach. Am J Clin Nutr 2000, 72:1291S-1296S.

10. Smith GD: Life-course approaches to inequalities in adult chronic disease risk. Proc Nutr Soc 2007, 66:216-236.

11. WHO: Diet, nutrition and the prevention of chronic diseases. In WHO Technical Report Series. Volume 916. Geneva; 2003, [http://whalibdoc.who.int/ trs/who_trs_916.pdf].

12. Hu FB: Dietary pattern analysis: a new direction in nutritional epidemiology. Curr Opin Lipidol 2002, 13:3-9.

13. Speck BJ, Bradley CB, Harrell JS, Belyea MJ: A food frequency questionnaire for youth: psychometric analysis and summary of eating habits in adolescents. J Adolesc Health 2001, 28:16-25.

14. Cutler GJ, Flood A, Hannan P, Neumark-Sztainer D: Major patterns of dietary intake in adolescents and their stability over time. J Nutr 2009, 139:323-328.

15. Nicklas TA, Webber LS, Thompson B, Berenson GS: A multivariate model for assessing eating patterns and their relationship to cardiovascular risk factors: the Bogalusa Heart Study. Am J Clin Nutr 1989, 49:1320-1327.

16. Li J, Wang Y: Tracking of dietary intake patterns is associated with baseline characteristics of urban low-income African-American adolescents. J Nutr 2008, 138:94-100.

17. Ritchie LD, Spector P, Stevens MJ, Schmidt MM, Schreiber GB, StriegelMoore RH, Wang MC, Crawford PB: Dietary patterns in adolescence are related to adiposity in young adulthood in black and white females. J Nutr 2007, 137:399-406.

18. Okubo H, Sasaki S, Murakami K, Kim MK, Takahashi Y, Hosoi Y, Itabashi M: Dietary patterns associated with functional constipation among Japanese women aged 18 to 20 years: a cross-sectional study. J Nutr Sci Vitaminol (Tokyo) 2007, 53:232-238.

19. Song Y, Joung H, Engelhardt K, Yoo SY, Paik HY: Traditional v. modified dietary patterns and their influence on adolescents' nutritional profile. $\mathrm{Br}$ J Nutr 2005, 93:943-949. 
20. Li SJ, Paik HY, Joung H: Dietary patterns are associated with sexual maturation in Korean children. Br J Nutr 2006, 95:817-823.

21. Kourlaba G, Panagiotakos DB, Mihas K, Alevizos A, Marayiannis K, Mariolis A, Tountas $Y$ : Dietary patterns in relation to socio-economic and lifestyle characteristics among Greek adolescents: a multivariate analysis. Public Health Nutr 2009, 12:1366-1372.

22. Barker ME, McClean SI, Thompson KA, Reid NG: Dietary behaviours and sociocultural demographics in Northern Ireland. Br J Nutr 1990, 64:319-329.

23. Aranceta J, Perez-Rodrigo C, Ribas L, Serra-Majem L: Sociodemographic and lifestyle determinants of food patterns in Spanish children and adolescents: the enKid study. Eur J Clin Nutr 2003, 57(Suppl 1):S40-S44.

24. Q3 Del Mar Bibiloni M, Martinez E, Llull R, Pons A, Tur JA: Western and Mediterranean dietary patterns among Balearic Islands' adolescents: socio-economic and lifestyle determinants. Public Health Nutr 2012, 15(4):683-692.

25. Craig LC, McNeill G, Macdiarmid JI, Masson LF, Holmes BA: Dietary patterns of school-age children in Scotland: association with socio-economic indicators, physical activity and obesity. Br J Nutr 2010, 103:319-334.

26. Lozada AL, Flores M, Rodriguez S, Barquera S: Dietary patterns in Mexican adolescent girls. A comparison of two methods. National Nutrition Survey, 1999. Salud Publica Mex 2007, 49:263-273.

27. McNaughton SA, Ball K, Mishra GD, Crawford DA: Dietary patterns of adolescents and risk of obesity and hypertension. J Nutr 2008, 138:364-370.

28. Kim JA, Kim SM, Lee JS, Oh HJ, Han JH, Song Y, Joung H, Park HS: Dietary patterns and the metabolic syndrome in Korean adolescents: 2001 Korean National Health and Nutrition Survey. Diabetes Care 2007, 30:1904-1905.

29. Song $Y$, Park MJ, Paik HY, Joung $H$ : Secular trends in dietary patterns and obesity-related risk factors in Korean adolescents aged 10-19 years. Int J Obes (Lond) 2010, 34:48-56.

30. Kamtsiurius $P$, Lange M, Schaffrath Rosario A: Der Kinder- und Jugendgesundheitssurvey (KiGGS): Stichprobendesign. Response und NonResponse-Analyse. Bundesgesundheitsbl-Gesundheitsforsch-Gesundheitsschutz 2007, 50:547-556.

31. Kurth BM, Kamtsiuris $P$, Holling $H$, Schlaud $M$, Dolle R, Ellert $U$, Kahl $H$, Knopf $H$, Lange $M$, Mensink GB, et al: The challenge of comprehensively mapping children's health in a nation-wide health survey: design of the German KiGGS-Study. BMC Public Health 2008, 8:196.

32. Mensink GB, Bauch A, Vohmann C, Stahl A, Six J, Kohler S, Fischer J, Heseker H: EsKiMo - the nutrition module in the German Health Interview and Examination Survey for Children and Adolescents (KiGGS). Bundesgesundheitsblatt Gesundheitsforschung Gesundheitsschutz 2007, 50:902-908.

33. Lange $M$, Kamtsiuris $P$, Lange $C$ : Schaffrath Rosario A, Stolzenberg $H$, Lampert T: [Sociodemographic characteristics in the German Health Interview and Examination Survey for Children and Adolescents (KiGGS) - operationalisation and public health significance, taking as an example the assessment of general state of health]. Bundesgesundheitsblatt Gesundheitsforschung Gesundheitsschutz 2007, 50:578-589.

34. Mensink GB, Haftenberger M, Thamm M: Validity of DISHES 98, a computerised dietary history interview: energy and macronutrient intake. Eur J Clin Nutr 2001, 55:409-417.

35. Krems C, Bauch A, Götz A, Heuer T, Hild A, Möseneder J, Brombach C: Methoden der neuen Nationalen Verzehrsstudie II. Ernährungs-Umschau 2006, 53:44-50

36. Hartmann BM, Bell S, Vásquez-Caicedo AL, Götz A, Brombach C: Der Bundeslebensmittelschlüssel - Aktuelle Entwicklungen, Potenzial und Perspektiven. Ernährungsumschau 2006, 53:124-129.

37. Kromeyer-Hauschild K, Wabisch M, Kunze D, Geller F, Geiß H, Hesse V, von Hippel A, Jaeger U, Dohnson D, Korte W, et al: Perzentile für den Bodymass-Index für das Kindes- und Jugendalter unter Heranziehung verschiedener deutscher Stichproben. Monatsschr Kinderheilkd 2001, 149:807-818.

38. Mensink GBM, Heseker H, Richter A, Stahl A, Vohmann C: Ernährungsstudie als KiGGS-Modul (EsKiMo) Forschungsbericht. Berlin, Paderborn: Robert KochInstitut, Universtität Paderborn; 2007, 1-137.

39. Hatcher L: A Step-by-Step Approach to Using the SAS System for Factor Analysis and Structural Equation Modeling. 9 edition. SAS Campus Drive, Cary, North Carolina: SAS Institute Inc; 2007.
40. Ambrosini GL, Oddy WH, Robinson M, O'Sullivan TA, Hands BP, de Klerk NH, Silburn SR, Zubrick SR, Kendall GE, Stanley FJ, Beilin LJ: Adolescent dietary patterns are associated with lifestyle and family psycho-social factors. Public Health Nutr 2009, 12:1807-1815.

41. Kohler S, Richter A, Lampert T, Mensink GB: Alcohol consumption among adolescents in Germany. Results of EsKiMo. Bundesgesundheitsblatt Gesundheitsforschung Gesundheitsschutz 2009, 52:745-752.

42. Alexy U, Sichert-Hellert W, Kersting M, Schultze-Pawlitschko V: Pattern of long-term fat intake and BMI during childhood and adolescence-results of the DONALD Study. Int J Obes Relat Metab Disord 2004, 28:1203-1209.

43. Okubo H, Sasaki S, Murakami K, Kim MK, Takahashi Y, Hosoi Y, Itabashi M: Three major dietary patterns are all independently related to the risk of obesity among 3760 Japanese women aged 18-20 years. Int J Obes (Lond) 2008, 32:541-549.

44. Mikkilä V, Räsänen L, Raitakari OT, Marniemi J, Pietinen P, Rönnemaa T, Viikari J: Major dietary patterns and cardiovascular risk factors from childhood to adulthood. The Cardiovascular Risk in Young Finns Study. Br J Nutr 2007, 98:218-225.

45. Willett WC: Nutritional Epidemiology. 2 edition. New York: Oxford University Press; 1998

46. Utter J, Scragg R, Ni Mhurchu C, Schaaf D: What effect do attempts to lose weight have on the observed relationship between nutrition behaviors and body mass index among adolescents? Int J Behav Nutr Phys Act 2007, 4:40.

47. Heitmann BL, Lissner L: Dietary underreporting by obese individuals-is it specific or non-specific? BMJ 1995, 311:986-989.

48. Kurth BM, Ellert U: Estimated and Measured BMI and Self-Perceived Body Image of Adolescents in Germany: Part 1 - General Implications for Correcting Prevalence Estimations of Overweight and Obesity. Obes Facts 2010, 3:181-190.

49. Brettschneider AK, Rosario AS, Ellert U: Validity and predictors of BMI derived from self-reported height and weight among 11- to 17-year-old German adolescents from the KiGGS study. BMC Res Notes 2011, 4:414

50. Schofield WN: Predicting basal metabolic rate, new standards and review of previous work. Hum Nutr Clin Nutr 1985, 39(Suppl 1):5-41.

51. Truthmann J, Mensink GB, Richter A: Relative validation of the KiGGS Food Frequency Questionnaire among adolescents in Germany. Nutr J 2011, 10:133.

52. Adams SA, Matthews CE, Ebbeling CB, Moore CG, Cunningham JE, Fulton J, Hebert JR: The effect of social desirability and social approval on selfreports of physical activity. Am J Epidemiol 2005, 161:389-398.

53. Martinez ME, Marshall JR, Sechrest L: Invited commentary: Factor analysis and the search for objectivity. Am J Epidemiol 1998, 148:17-19.

54. McCann SE, Marshall JR, Brasure JR, Graham S, Freudenheim JL: Analysis of patterns of food intake in nutritional epidemiology: food classification in principal components analysis and the subsequent impact on estimates for endometrial cancer. Public Health Nutr 2001, 4:989-997.

55. Michels KB, Schulze MB: Can dietary patterns help us detect diet-disease associations? Nutr Res Rev 2005, 18:241-248.

\section{Pre-publication history}

The pre-publication history for this paper can be accessed here: http://www.biomedcentral.com/1471-2431/12/35/prepub

\section{doi:10.1186/1471-2431-12-35}

Cite this article as: Richter et al.: Dietary patterns of adolescents in Germany - Associations with nutrient intake and other health related lifestyle characteristics. BMC Pediatrics 2012 12:35. 